\title{
Comment: Acts of Faith and Substantiation
}

\author{
By Rupert Cox (University of Manchester)
}

\begin{abstract}
'The magician heals a sick person by the laying on of hands; the surgeon cuts into the patients body. The magician maintains the natural distance between the patient and himself, though he reduces it very slightly by the laying on of hands, he increases it by virtue of his authority. The surgeon does exactly the reverse; he greatly diminishes the distance between himself and the patient by penetrating into the patient's body and increases it but little by the caution with which his hands moves among the organs... magician and surgeon compare to painter and camera man. The painter maintains in his work a natural distance from reality, the camera man penetrates deeply into reality.' (Benjamin 1969: 233).
\end{abstract}

The three papers presented, reproduce in different ways the distinction that Benjamin is working through in the passage quoted above, between acts of investigation that are sensitive to the surface of things, and those which are penetrative and invasive. The nature of materials, the capacities of the mindful body and the promise of technology are all imbricated in this distinction, which in the context of the subjects being discussed in these papers, proposes that the kind of anthropology carried out touchingly, curiously, and empathetically performs a kind of magic. This is the magic of resemblance, by which the descriptions, of a children's oncology ward, religious communities in Belleville and Soho road, and material's libraries, become avenues to a sensuous apperception of, illness, faith and matter. The magic of resemblance or mimetic power of these three accounts is dependent on their researchers contacts with what Michael Taussig, following Benjamin (1969), has called the 'physiognomic aspects of social worlds' (1992). The kind of knowledge derived from such contact is ontologically different from the kind of knowledge based on distanced observations, which claim to cut into, and see inside the social body, and where the interpretative effects of description are produced by and contingent upon the rhetorical authority of 'scientism' (Okely 1975).

As the authors' note here, what is often missing in such accounts is the acknowledgement of subjectivity, materiality and the emotional relationality of fieldwork. In the account of an oncology ward in a South African hospital, the notion of touch is regarded as more than an institutional instrument of diagnosis and care, and becomes a means of exploring the nature of illness experienced among children. The danger of such an approach, it is argued here, is not of what might be called a 'touchy feely' anthropology, but rather of shutting oneself off from an anthropology that is empathetic and receptive, something which in circumstances such as this hospital ward would be unconscionable. This is an important argument, but also requires a difficult position for the researcher to take as it might be construed as implying that empathy is a correlative of only a certain kind of openness of touch, 
reducing the restrictive, procedural, touching practices of the hospital staff to a functional role. The question raised in this paper about positioning is also a question about representation, and in the paper on 'the field of faith' a case is made for descriptive writing and photography as providing a 'deeper insight' into two different religious communities. As the project and the methods emanate from personal experience and individual vision, it is difficult to separate out the insight that we clearly have into the background and feelings of the researcher in the field from the insight into the communities presented. In terms of vision, the communities are evident and distinguishable by the different pictorialisms of writing and photography; which is a strategy that could be made more interpretative if we knew why one method was chosen above the other in each case. It is not clear why this separation is necessary, for when photography and writing are directly combined, as in the photographic essay, it is possible to construct a creative tension between these two media that may constrain and productively direct what the author calls the 'desire to imagine what is out of the frame'. Left unchecked these two modes of en-visioning are open to the charge of impressionism, and while they may originate in a personal vision and also enable a reflection on the limits and possibilities of what might be called 'phenomenological methods', it is important to know how they also substantiate the complex worlds of these two streets. Such substantiation may be, as it is presented here, about the description of surfaces, fleshing out the contingencies of personal encounters and the view of the camera, so that we appreciate that it is by our own willingness to have faith in these impressions that we may understand something about these communities as fields of faith in and of themselves.

The relationship between substance and faith is highlighted in the third essay, which deals with the attitudes and practices of scientists and artists that are brought to bear on materials libraries. As the author makes clear there is no simple transfer of knowledge, or indeed agreement on knowledge itself, between the positions that these communities occupy - for they engage the substance of matter through modes of visualization and touch that are often at odds with each other. The scientific ability to penetrate, probe, and ascribe epistemic order to materials is premised on a visualism that cannot easily accommodate the touching forms of curiosity and the wonder through which such materials were arranged in the past, which scientists like Mark Miodownik are acknowledging in their encouragement of experimentation and play as ways of understanding. As in the other papers presented here, vision and tactility are counter-posed, and the question is how their reconciliation may offer productive opportunities for anthropological method as well as insight into the subjects under consideration. It may be that while the tensions between vision and touch articulated in these three papers are useful for sorting out some of the disciplinary concerns of anthropology, they may be productively overcome by thinking in terms like 'the tactility of vision' (Taussig 1993: 26), and therefore of the surgeon and the magician; that is, it is important to think of vision and touch not as representing opposed forms of knowledge, but as intermediaries between the surface and interiority of meaning. It is an interstitial space which these papers suggest may be occupied and traversed by the anthropologist who is prepared to: dive into the ethical dilemmas of embracing a sick child in a South African hospital; connect the acts of faith required in appreciating the impressionism of photography and writing with insights into two separate faith communities; and to immerse themselves in the substance of materials as a way of understanding the intersections of art and science. 


\section{About the Author}

Dr. Rupert Cox is a lecturer in the Social Anthropology department at the University of Manchester. He received his MA and Ph.D. in Social Anthropology from the University of Edinburgh, finishing in 1998. He has had fellowships with the Royal Asiatic Society and the Japan Society for the Promotion of Science, grants from the British Academy, Japan Foundation, Economic and Social Research Council, and Wellcome Trust; taught at Edinburgh, Oxford Brookes and London University (SOAS) and held a visiting position at Okinawa College of Technology. He is codirector of the film company 'Native Voice Films' and has been involved in a number of different film, sound-art and gallery productions.

\section{Bibliography}

Benjamin, W. (1969) [1955], 'The Work of Art in the Age of Mechanical Reproduction', in Illuminations, Schocken, New York.

Okely, J. (1975), The Self and Scientism, JASO, 6,3. 1983

Taussig, M. (1993), Mimesis and Alterity, A Particular History of the Senses, Routledge Press

Taussig, M. (1992), 'Physiognomic Aspects of Visual Worlds', Visual Anthropology Review, 8 (1): 15-28 